\title{
PRIMEIROS CAASOS AGUDOS AUTÓCTONES DA DOENÇA DE CHAGAS NO MARANHÃ̃O E INQUÉRITO SORO-EPIDEMIOLÓGICO DA POPULAÇÃO
}

\author{
Antonio Rafael da Silva, José Ribamar Borges Mendes, Maria Luiza \\ Mendonça, Raimundo Nonato Cutrim e Reginaldo Peçanha Brazil
}

\begin{abstract}
Os autores apresentam os primeiros casos autóctones da forma aguda da doença de Chagas no Estado do Maranhão. Três casos originários da Ilha de São Luís eo outro procedente da localidade de Bacurituba, municipio de Cajapió na região da Baixada Maranhense. O resultado do inquérito sorológico, utilizando-se a reação de imunofluorescência indireta em 213 habitantes das localidades de Rio Grande e Caúra, onde foram diagnosticados os casos autóctones na Ilha de São Luís, revelou $3(1,4 \%)$ positivos.

Palavras chaves: Trypanosoma cruzi. Doença de Chagas. Maranhão. SoroEpidemiologia.
\end{abstract}

A doença de Chagas tem sido considerada como inexistente no Estado do Maranhão ${ }^{1}$. O diagnóstico de quatro casos agudos motivou a realização de um estudo epidemiológico. Os aspectos de transmissão e distribuição de triatomíneos na Ilha de São Luis serão analisados em outro trabalho ${ }^{2} \mathrm{e}$ a investigação sorológica nos habitantes das localidades onde ocorreram os casos de doença de Chagas é um dos motivos deste trabalho.

\section{Relatos de Casos}

Caso 1 - A.L.P.C., 5 anos, masculino, branco, natural da localidade de Caúra, município de Ribamar (llha de São Luis), Maranhão onde reside.

Início da doença em agosto de 1975 , com febre moderada, contínua, acompanhada de dor abdominal difusa e calafrios. No quarto dia da doença, houve desaparecimento da febre, tendo nessa ocasião sido administrado $150 \mathrm{mg}$ de Amodiaquina. Três dias após, apresentou febre, edema palpebral à direita e discreto cansaço, tendo então sido internado.

Ao exame fisico mal estado geral, dispnéia, edema subcutâneo generalizado, micropoliadenopatia, temperatura $38,5^{\circ} \mathrm{C}$, tensão arterial $80 \times 40 \mathrm{mmHg}$, 136 batimentos cardiacos por minuto. Ictus cordis visivel e palpável no $3^{\circ}$ espaço intercostal esquerdo, propulsivo e desviado para dentro da linha hemiclavicular esquerda, 3\% bulha audivel. Abdome aumentado de volume, com fígado palpável a $5 \mathrm{~cm} \mathrm{da}$ reborda costal direita e doloroso. Baço impalpável. Anemia e linfocitose de 53\%. Raios X de tórax evidenciou aumento global da área cardiaca. $\mathrm{O}$ ele-

\footnotetext{
Trabalho realizado na Disciplina de Doenças Infecciosas e Parasitárias do Departamento de Patologia da Universidade Federal do Maranhão em colaboração com a Superintendência das Campanhas de Saúde Pública (SUCAM).

Endereço para correspondência: Departamento de Patologia, Universidade Federal do Maranhão-65.000 São Luis-MA.

Recebido para publicação em 16/4/84
}

trocardiograma mostrou taquicardia sinusal e QRS de baixa voltagem. A pesquisa de $T$. cruzi em sangüe periférico, o xenodiagnóstico e a imunofluorescência indireta foram positivos.

Teve alta a pedido. Devido a piora progressiva, no 30 \% dia iniciou benzonidazol na dose de $8 \mathrm{mg} / \mathrm{kg} /$ dia, diuréticos e digitálicos. Com esse tratamento houve regressão da dispnéia e da febre. $O$ eletrocardiograma feito após o inicio do tratamento, demonstrou BAV de $1 \%$ grau. A medicação foi suspensa pelos familiares 20 dias após o início do tratamento, com subseqüente agravamento do quadro, vindo a criança a falecer.

$\mathrm{Na}$ época do início da doença, seu pai teve quadro febril que durou alguns dias e cessou espontâneamente, sem razão aparente para justificá-lo.

Caso 2 - J.R.M., 29 anos, masculino, branco, lavrador, maranhense, residente na localidade de Rio Grande, municipio de São Luis.

Início da doença em junho de 1975, com febre moderada, intermitente, acompanhada de calafrios, cessando espontaneamente no fim de quatro dias, para voltar a se manifestar 12 dias após, mais acentuada e permanecendo por 5 dias, ocasião em que apresentou edema de membros inferiores atingindo até os joelhos, mialgia, astenia e edema de face.

Ao exame físico estava em regular estado geral, temperatura de $37^{\circ} \mathrm{C}$, tensão arterial $120 \times 70 \mathrm{mmHg}$. Coração em ritmo regular, bulhas hipofonéticas, Gânglios palpáveis a $2 \mathrm{~cm}$ da reborda costal direita, indolor. Baço impalpável. Discreto edema de membros inferiores. $O$ hemograma mostrou anemia $e$ eosinofilia de $38 \%$. O eletrocardiograma revelou BAV de 1. grau. Raio $\mathrm{X}$ de tórax normal. Pesquisa de $T$. cruzi em sangue periférico, assim como xenodiagnóstico e imunofluorescência indireta foram positivos. Medicado com benzonidazol, na dose de $8 \mathrm{mg} / \mathrm{kg} / \mathrm{dia}$ durante 60 dias.

Caso 3 -A.J.B., 32 anos, masculino, branco, funcionário público, maranhense e residente em São Luis.

Após 7 dias de permanência na localidade de 
Relato de Caso. Silva AR, Mendes JRB, Mendonça ML, Cutrim RN, Brazil RP. Primeiros casos agudos autóctones de doença de Chagas no Maranhão e inquérito soroepidemiológico da populaçäo. Revista da Sociedade Brasileira de Medicina Tropical 18: 269-270, Out-Dez, 1985

Bacurituba, município de Cajapió, na Baixada Maranhense, onde praticava caçadas noturnas, apresentou em abril de 1980 , febre inicialniente moderada chegando com a evolução a atingir $39^{\circ} \mathrm{C}$, irregular, assim como edema palpebral no olho esquerdo, inicialmente discreto, tornando-se em seguida intenso e arroxeado, ocluindo a fenda palpebral. Neste periodo apresentou episódios de lipotimia.

Ao exame físico apresentava-se em bom estado geral, temperatura de $38^{\circ} \mathrm{C}$, pulso de 100 batimentos, ritmo cardíaco regular. $O$ fígado era palpável a $4 \mathrm{~cm}$ da reborda costal direita, indolor. Baço impalpável. $\mathrm{O}$ hemograma apresentou série vermelha sem alteraçãoe eosinofilia de $54 \%$. O eletrocardiograma mostrou taquicardia sinusal. Raios $\mathrm{X}$ de tórax normal. Pesquisa de $T$. cruzi em sangue periférico, bem como xenodiagnóstico e imunofluorescência indireta foram positivos. Medicado com benzonidazol na dose de $8 \mathrm{mg} / \mathrm{kg} /$ dia, durante 60 dias.

Caso 4-A.A.C., 57 anos, masculino, branco, lavrador, residente na localidade de Pedrinhas, município de São Luís.

Início da doença em junho de 1983, com febre moderada, contínua que cedia com uso de antitérmicos. No 10. dia de doença, fez uso de Aralen injetável durante 48 horas, melhorando a febre, mas continuaram os calafrios, ocasião em que começou a apresentar sudorese noturna, cefaléia intensa e sensação de desmaios.

Ao exame físico bom estado geral, eupnéico, temperatura $37^{\circ} \mathrm{C}$, tensão arterial $150 \times 90 \mathrm{mmHg}$, pulsos palpáveis, amplitude diminuida nas extremidades distais. Ausculta cardiaca com 100 batimentos por minuto, bulha clangorosa no foco aortico, sopro sistólico nos focos da base e 3 a bulha audivel. Abdome de forma e volume normais, fígado palpável $3 \mathrm{~cm}$ da RCD indolor. Baço impalpável. O hemograma mostrou eosinofilia de $46 \%$. Raios $\mathrm{X}$ de tórax normal. Eletrocardiograma com taquicardia sinusal. A pesquisa de $T$. cruz $i$ em sangue periférico foi positiva em várias amostras e imunofluorescência positiva. Medicado com benzonidazol na dose de $8 \mathrm{mg} / \mathrm{kg} / \mathrm{dia}$ durante 60 dias.

Obtiveram-se amostras de sangue periférico em papel de filtro que foram colhidas por punção digital de 171 habitantes de Rio Grande (71,7\% da população) e 42 habitantes de Caúra $(85,3 \%)^{6}$ e examinadas pela técnica de imunofluorescência indireta no Departamento de Medicina Preventiva da Universidade Fe deral do Rio de Janeiro.

A reação foi positiva em $3(1,4 \%)$ entre 213 individuos das duas localidades. Dos 3 positivos, dois eram adultos do Caúra e o terceiro, uma criança da localidade do Rio Grande.

\section{COMENTÁRIOS}

O acompanhamento dos casos diagnosticados a partir de 1975 revela que JRM (caso 2) apresenta BAV de 1. grau e como os outros permanece assintomático e em plena atividade.

$O$ retardo desta publicação ocorreu em função de captura de triatomíneos ser negativa e não se conhecer no Maranhão a sua distribuição geográfica. Presentemente sabe-se que das 42 espécies existentes no Brasil $^{4}$, 15 delas já foram encontradas naquele Estado $^{5}$ e dentre elas as 5 de maior importância epidemiológica 35 . Recente trabalho realizado na Ilha de São Luís ${ }^{2}$, revela a distribuição de triatomíneos.

\section{SUMMARY}

The authors describe the first autochthonous acute cases of Chagas' disease in the State of Maranhào. Three cases from the island of São Luis and the fourth from Bacurituba, in the low land area of the State.

The results of indirect immunofluorescence test in 213 inhabitants of São Luis have shown $3(1,4 \%)$ positive.

Key words: Chagas' disease. Maranhão. Seroepidemiology.

\section{REFERÊNCIAS BIBLIOGRÁFICAS}

1. Barreto MP. Epidemiologia. In: Brener Z, Andrade Z (ed) Trypanosoma cruzi e Doença de Chagas. Editora Guanabara Koogan, 1979.

2. Brazil RP, Da Silva AR, Albarelli AL, Vale JF. Distribuição e infecção dos triatomíneos por Trypanosoma cruzi na Ilha de São Luis, Maranhão. Revista da Sociedade Brasileira de Medicina Tropical 18: 257-260, 1985.

3. Bustamante FM. Distribuição geográfica dos transmissores da doença de Chagas no Brasil e sua relação com certos fatores climáticos. Epidemiologia e profilaxia da enfermidade. Revista Brasileira de Malariologia e Doencas Tropicais 9: 191-211, 1957.

4. Lent $\mathrm{H}$, Wygodzinsky $\mathrm{P}$. Revision of the Triatominae (Hemiptera, Reduvidae) and their significance as vectors of Chagas' disease. Bulletin of The American Museum of Natural History, 163: 125-520, 1979.

5. Silveira AC, Feitosa VR, Borges R. Distribuiçào de triatomíneos capturados no ambiente domiciliar, no periodo 1975/83, Brasil. Revista Brasileira de Malariologia e Doenças Tropicais 36: 15-312, 1984.

6. Souza SL, Camargo ME. The use of filter paper blood smears in the practical fluorescent test for American trypanosomiasis serodiagnosis. Revista do Instituto de Medicina Tropical de São Paulo 8: 255-258, 1966. 